\title{
The use of Peripheral Blood-Mononuclear Cells in Scleroderma patients: an observational preliminary study
}

Sara Carella ( $\sim$ carellasara@gmail.com )

Universita degli Studi di Roma La Sapienza https://orcid.org/0000-0001-8034-9584

\section{Caterina Rossi}

Sapienza University of Rome

Diego Ribuffo

Sapienza University of Rome

Maria Giuseppina Onesti

Sapienza University of Rome

Technical advance

Keywords: Peripheral Blood Mononuclear Cells, Macrophages, Immunomodulation, Systemic Sclerosis, Cell Therapy, Wound Healing

Posted Date: August 25th, 2020

DOl: https://doi.org/10.21203/rs.3.rs-53467/v1

License: (c) (i) This work is licensed under a Creative Commons Attribution 4.0 International License. Read Full License 


\section{Abstract \\ Background}

Systemic sclerosis (SSc) is a systemic autoimmune disease characterized by vasculopathy and excessive production of collagen, which lead to skin and visceral fibrosis. The aim of our study is to assess the potential benefits of peripheral blood mononuclear cells (PB-MNCs) implants in the treatment of clinical manifestations such as mouth impairment, hand disability, digital ulcers and Raynaud's phenomenon in Scleroderma patients.

\section{Methods}

From February 2016 to May 2019, 10 female patients were enrolled from the outpatient clinic of the Plastic Surgery Unit of Sapienza University of Rome. Parameters evaluated were: patients' disability, using the Health Assessment Questionnaire (HAQ) disability index (DI) and the scleroderma HAQ (sHAQ); mouth opening capacity, by measuring the maximum interincisal distance and the mouth perimeter; hand mobility, assessed with clinical exam and the Hand Mobility in Scleroderma (HAMIS) scale; Raynaud's phenomenon, evaluated through nailfold capillaroscopy; digital ulcers, examined through their features and incidence of appearance. SPSS software was used for a simple descriptive statistical analysis performed by the Student's paired t-test. $P$ values less than 0.05 were considered statistically significant.

\section{Results}

The treatment showed a significant improvement of all the parameters evaluated at 1-year follow-up, it was well-tolerated by all the patients and the only complications noticed were small areas of ecchymosis.

\section{Conclusions}

Our results suggest that PB-MNCs injection could represent a treatment option to take into account for SSc patients. The procedure we used is easy and fast to perform, minimally invasive and not-operator dependent. We hope our observational and preliminary study could be considered as a starting point for further research studies.

\section{Background}

Systemic sclerosis (SSc) is a systemic autoimmune disease of unknown cause characterized by vasculopathy and excessive production of collagen [1]. Several pathophysiological processes are involved in its development such as cellular and humoral autoimmunity, vascular injury, and tissue fibrosis. They all lead to a connective tissue disease characterized by a pathological thickening and 
tethering of the skin and by the involvement of internal organs (gastrointestinal tract, heart, lungs and kidneys) [2].

Due to its low-frequency, insidious onset, variable presentation and the lack of uniformity in its diagnostic criteria, it is difficult to study its epidemiological features. However, its prevalence ranges from $7 /$ million to 489 /million and its incidence from 0.6 /million/year to 122 /million/year [2]. There are many geographical variations, with higher prevalence in the USA and Australia, then in Japan and Europe. Age of onset is most commonly in the range of 30-50 years. The prevalence in first degree relatives is significantly higher than in the general population ( $1.6 \mathrm{vs} 0.026 \%$ ) and like other connective tissue disorders, SSc is also predominant in females with ratios of women to men between 5 and 14:1 [3].

The ACR (American College of Rheumatology) criteria published in 1980 were the first used to classify these patients, but the 2013 EULAR (European League Against Rheumatism)/ACR classification criteria showed a higher sensitivity. The ACR criteria are limited by their lack of sensitivity for mild and early cases of SSc [4].

The term "Scleroderma" derives from the most characteristical feature of the disease - skin thickening. Raynaud's phenomenon occurs as the first clinical feature of the pathology, simultaneously with skin thickening or shortly prior to it. It is tipically present in the digits of the hand but can also affect the feet, the earlobes, the tip of the nose and the tongue. In Scleroderma patients it often leads to the onset of trophic changes in the fingertips, in the form of necrosis, hard-to-heal erosions and ulcers, and residual scars. Finger contractures (sclerodactyly) develop with the progression of the disease. The range of finger motion is limited, while trophic disorders contribute to bone destruction and shortening of distal phalanges (acroosteolysis) [5].

Restricted hand movements are finger flexion and extension, abduction of the thumb, dorsal extension and volar flexion of the wrist, pronation and supination of the forearm, ability to make a thumb pincer grip and to make finger abduction.

Skin sclerosis may also affect the face, including the lips. The most typical facial features associated with SSc are teleangiectasias, shrunken nose, microcheily, reduced mouth opening (microstomy), and microglossy. In addition, cutaneous wrinkles around the mouth disappear and there may be a radial furrowing around the lips: the face of these patients becomes amimic. Among the other skin manifestations there are changes in skin pigmentation, hair loss, dryness due to the loss of sebaceous glands, and joint contracture.

Facial involvement and oral complications can lead to problems with oral hygiene and in eating, to aesthetic changes and impairment of the patient's self-image. Moreover, sclerosis of the extremities is highly disabling and results in significant dysfunction. Due to these disabilities, several studies are quite concordant in remarking the importance of a multidisciplinary therapy and tailored approach. The usefulness of pharmacological, pathogenetic and symptomatic treatments (immunosuppressor, immunomodulators, antifibrotics, corticosteroids, plasmapheresis, phototherapy, anti-inflammatory, 
vasoactive, and analgesic drugs), as well as some precautionary measures and a proper life-style (such as avoiding cold or smoke), may be important to prevent and treat Scleroderma skin lesions [6].

In addition to these systemic approaches, local treatments should be considered in more severe and nonhealing lesions [6]. Several regenerative cell-based techniques were described for the treatment of Scleroderma patients, mostly with autologous fat (lipofilling), stromal vascular fraction (SVF) and/or adipose-derived stomal cells (ASCs) from adipose tissue [7-12].

New point of care device based on peripheral blood selective filtration technology has been developed to produce fresh autologous peripheral blood-mononuclear cells (PB-MNCs) for use in human cell therapy applications. Cell concentrate produced by this innovative technology has been extensively studied in term of characterization and adequate potency in therapeutic angiogenesis in vitro and in vivo [13]. This tecnique is less invasive in comparison to adipose tissue transplantation, faster, not operator-dependent and user-friendly. Promising results on the wound healing were obtained by this cellular concentrate in different clinical trials on critical limb ischemia patients, [14-16]. It has been observed that PB-MNCs are able to induce therapeutic angiogenesis to promote collateral vessel formation through paracrine effect $[17,18]$. PB-MNCs release growth factors, cytokines, messenger molecule [19] as well as exosomes [20], as also demonstrated in a wound healing animal model [21]. Monocyte/macrophages and lymphocytes, in particular Treg populations, play a key role in tissue regeneration in non-healing trophic lesions through macrophages inflammatory M1 polarization to the M2 regenerative phenotype [22]. Growing evidence suggests also a key role of limphocytes in angiogenesis and in tissue regeneration[23-26]. PB-MNCs could have an indication of use in auto-immune-based diseases where there is a vascular and/or microcirculation problem [27-29] not only for their angiogenic capacity but also for their ability to regenerate tissues and restore the correct $\mathrm{M} 1 / \mathrm{M} 2$ balance, always compromised in the non-healing lesions of patients suffering from these pathologies, as recently published [30].

For the first time at the best of our knowledge we reported our experience on the use of PB-MNCs implants in order to treat open mouth impairment, hand disability, digital ulcers and Raynaud's phenomenon.

Primary outcomes were as follows: improvement of hand function and mouth opening. The secondary outcome was the gaining of a better quality of life.

\section{Methods}

From February 2016 to May 2019, 10 female patients, fulfilling ACR criteria [31] and classified as having diffuse cutaneous Scleroderma (dcSSc) [32,33], were enrolled from the outpatient clinic of the Plastic Surgery Unit of Sapienza University of Rome. These patients had advanced systemic sclerosis-related perioral thickening, mouth opening restriction (2 out of 10 patients) and hand mobility limitation, Raynaud's phenomenon, and digital ulcers. The proposed treatement consisted of PB-MNCs injections in order to treat the above manifestations. The mean age was 50,2 years (range: 21-68) and the average disease length was 7 years (range: 3-11). They agreed by a written informed consent to participate in the 
study, which was conducted in full accordance with ethical principles, including the World Medical Association Declaration of Helsinki.

For each patient, during the first evaluation, demographic, anamnestic, and clinical data were collected and recorded, using a written form that was held securely, thus being accessible only to study investigators (Table 1).

\subsection{Inclusion criteria}

Age >18 years, stable phase of disease, SSc diagnosis with hands and/or perioral involvement; no possibility to perform lipofilling (lack of adipose tissue, BMl<20).

\subsection{Exclusion criteria}

Age $>75$ years, pregnancy, or lactation; immunomodulating or immunosuppressive therapy within the last 4 weeks and any topical therapy within the last 2 weeks except for the use of emollients, comorbidities contraindicating the treatment (active malignancy, bone marrow or hematologic disorders, active infections).

\subsection{Disability Evaluation}

All patients were evaluated for the following parameters before the procedure (T0), and 1 week (T1), 1 month (T2), 3 months (T3), 6 months (T4) and 1 year (T5) after.

2.3.1 Health Assessment Questionnaire (HAQ)Disability Index (DI) and scleroderma HAQ (sHAQ): These instruments are increasingly utilized to assess Scleroderma patients in randomized trials. The HAQ-DI contains 8 domains of activity (dressing, arising, eating, walking, hygiene, reach, grip, and common daily activities) each of which has at least 2 questions, for a total of 20 items. For each item patients report the amount of difficulty experienced performing the activity with 4 possible responses, ranging from 0 (without any difficulty) to 3 (unable to do). A mean score is calculated for each domain ranging from 0 to 3. A composite HAQ-DI score is calculated by dividing the summed domain scores by the number of domains answered. The composite score is reported on an ordinal scale, falling between 0 and 3 . The scores are interpreted as 0 (no impairment in function) to 3 (maximal impairment of function). The HAQDI also contains a Visual Analogue Scale (VAS) that patients use to report the amount of pain experienced in the past week [34]. The sHAQ is more specific for SSc, as it adds 5 visual analogue scales to HAQ, evaluating also Raynaud's phenomenon, digital ulcers, gastrointestinal, lung symptoms, and overall disease severity [35].

2.3.2 Mouth opening capacity. it was evaluated by measuring, at baseline and at each follow-up, the maximum interincisal distance and the mouth perimeter. This latter one was derived by the ellipse geometrical formula, that is $2 \mathrm{pÖ}\left[\left(a^{2}+b^{2}\right) / 2\right]$, where " $a$ " stands for the semi-major axis (half of the distance between upper and lower lip, at maximally opened mouth), and " $b$ " stands for the semi-minor axis (half of the distance between the opposite lip commissures). The software used was Microsoft Mathematics 4.0. 
2.3.3 Hand Mobility in Scleroderma (HAMIS): this is a performance-based test, found to be a reliable and valid tool to assess hand function in SSc patients. It is composed of 9 items, assessing both hands. The different performance areas of HAMIS test are composed of different-sized grips and different movements, all related to tools and activities that are part of daily occupations. Each exercise is graded on a $0-3$ scale (from $0=$ normal function to $3=$ inability to perform the task), with a total possible score of 27 for each hand [36] (Table 2).

2.3.4 Raynaud's phenomenon: its frequency and duration were assessed through patient reported data and its severity with nailfold capillaroscopy.

2.3.5 Cutaneous digital ulcers. they were examined through anamnestic and clinical findings. Their incidence of appearance was recorded.

2.4 Cell therapy: autologous PB-MNCs concentration. A disposable point of care selective filtration system certified for human cell therapy was used to concentrate PB-MNCs (Monocells - Pall Celeris Athena Biomedical Innovations) (Figure 1). This system was fully characterized and the PB-MNCs obtained were tested positively for angiogenic potential in vitro and in vivo [13].

Fluoresence-activated cell sorting (FACS) analysis of total nuclear cells (TNCs) obtained by selective filtration confirmed the presence of CD45+CD3 T lymphocytes, CD45+CD14+ monocytes, CD45+ CD19+ B lymphocytes, CD45+CD66b+ neutrophil granulocytes, CD3-CD16+CD56+ natural killer, CD45+CD34+ stem cell component, CD4+KDR+ and CD34+KDR+ endothelial progenitors. Pall Celeris filtration system cell concentrate output is enriched 2.97-fold in TNC, 4.2- fold MNCs, 3,94 fold monocytes, I 4,25 fold limphocytes, while CD34+ progenitor cells subpopulation are enriched 5,6 fold as reported [13].

In a sterile operating theatre PB-MNCs were obtained by a peripheral 100-120 ml venous blood sample following the original instruction for use. The procedure was performed as follows: $120 \mathrm{ml}$ of ACD (Acid Citrate Dextrose) anticoagulated blood were transferred to the upper bag of the system which was hang up to let the blood flew by gravity through the filter below. The selective membrane retained TNCs and the residual blood flew to the waste blood bag under the filter. After filtration, which took around 10-15 min, a $10 \mathrm{ml}$ of saline solution backwash allowed to harvest the PB-MNCs from the filter, resulting in 8-10 ml of cell concentrate collected in a cell recovery bag and ready to be injected. $0,25 \mathrm{ml}$ of the cell concentrate obtained was injected in each site, containing a mean average count of $20,8+/-0,1 \times 10^{6} / \mathrm{ml} \mathrm{TNC}, 10,6+/-$ $0,2 \times 10^{6} \mathrm{MNC}$ and $137+/-0,3 \times 10^{3} / \mathrm{ml} \mathrm{CD} 34+[13]$.

\subsection{Cell therapy: autologous PB-MNCs implants}

For hands, each injection was performed with a $21 \mathrm{G}$ needle. Subcutaneous injections were performed at the bases of the fingers and proximally to the digital ulcers at level of the perilesional skin. The total amount of cell concentrate we injected, varied from 3 to $5 \mathrm{ml}$, depending on the single case. For mouth, injections were performed at the subcutaneous level of selected perioral areas, using a blunt cannula of 2 
$\mathrm{mm}$ in diameter. The cannula was inserted in 2 symmetric sites located just proximally to the labial commissures.

Six areas were identfied: two in the upper lip and two in the lower lip (two lateral for each lip). The remaining 2 areas were represented from the nasolabial fold and a line extending from the labial commissure toward mandibular border. Perioral region was injected using many radiating passages at the subcutaneous level for a total of $2 \mathrm{~mL}$.

The study design foresaw the performance of the treatment once a month, for a total of 3 to 4 sessions, to be evaluated depending on the single case outcome.

\subsection{Statistical analysis}

SPSS software (IBM Corp., Armonk, NY) was used for a simple descriptive statistical analysis. Absolute scores and their changes from TO to T5 were evaluated. The Shapiro-Wilk test was used to verify the normal distribution of continuous variables. Consequently, data were analyzed using Student's paired $t$ test. $P$ values less than 0.05 were considered statistically significant.

\section{Results}

The treatment showed a significant improvement of all the parameters evaluated (Table 3).

In all patients HAMIS scale decreased $(p=0,0026)$, reflecting a better hand function. The frequency of Raynaud's phenomenon appeared to be reduced $(p=0,0023)$ : in one patient expecially there was a reduction from an average of 15 episodes per day to a maximum of 5 episodes per day after the PBMNCs therapy. Six patients were affected by multiple digital ulcers at baseline, after 12 months from the autologous implant only three of them had one digital ulcer left $(p=0,0044)$ (Figures $2 A-B)$.

The improvement of mouth opening was observed in two patients: an icreased mouth perimeter was recorded (patient A mouth perimeter: from T0 $=10,84$ to $T 5=13,66$; patient $B$ mouth perimeter: from $T 0=$ $9,72$ to $T 5=12,87$ ) (Figures $3 A-D)$. Patients reffered improving in oral igiene and bite function.

We also recorded a meaningful increase of the HAQ-DI composite score $(p=0,0017)$.

The treatement was well-tolerated by all the patients, the only complications noticed were small areas of ecchymosis. Three patients claimed to be very satisfied with the procedure, five claimed to be satisfied, and two were moderately satisfied.

\section{Discussion}

Over the years several alternatives to treat the cutaneous and vasculopathy-related manifestations of SSc were suggested. Autologous fat transplantation has become the first-choice technique in the treatment of SSc cutaneous lesions. This approach, using the patient's own body fat as a natural filler to achieve 
structural modifications, takes advantage of its abundance and accessibility and avoids complications associated with foreign materials. Elective liposuction for fat transplantation is nowadays considered a safe and well-tolerated procedure [12], Unfortunatelly, adipose tissue is not available in every patient, as it happens for patient lacking in adipose tissue $(\mathrm{BMI}<20)$.

Nevertheless, some studies described the potential role of cell-based therapies, such as ASCs and SVF based therapy [10-12].They require less invasive harvesting techniques than the ones used when bone marrow is the primary source of mesenchymal stromal cells (MSCs) and are particularly useful in SSc patients with a grade of skin fibrosis that could not even permit the insertion of the smallest liposuction cannula.

Moreover point of care devices have been placed on the market for the production of micro fragmented adipose tissue, also called nano graft, and adipose cells concentration system containing SVF [37].

The main disadvantages of ASCs-based therapy are represented by high costs, due to cell preparation in certified Good Manufacturing Practice (GMP) laboratories, and its need to be performed in two separate sessions, thus increasing the patient discomfort.

Notably, several papers showed that a main mechanism of action of MSCs from adipose tissue, is to promote tissue regeneration through M2 polarization [38-40], but hypoxia reduces their capability to polarize macrophages in the M2 phenotype [41] while for the PB-MNCs hypoxia is a physiological trigger for angiogenesis [42-46].

Moreover, Navarro et al recently showed that the angiogenic capacity of adipose tissue is related to the monocytes CD14 + population contained in SVF, which is more efficient in inducing angiogenesis than the ASCs [47].

PB-MNCs rappresent a new promising autologous therapy used in critical limb ischemia [14-16, 48], diabetic foot [49-51] and chronic ulcers $[52,53]$. The angiogenic and arteriogenic potency of monocytes is well described $[17,18,20,21,54]$. More recently several studies also indicate an angiogenic function of specific limphocytes populations [25,55-58].

It is interesting to note that PB-MNCs efficacy was also reported in a large meta-analisys in no option critical limb ischemia patients showing that PB-MNCs may outperform bone marrow-mononuclear cells and mesenchymal stem cells in reducing significately limb amputation [48].

With our preliminary study we thought to exploit the PB-MNCs capability to induce angiogenesis widely described in literature $[21,59-61]$ in order to treat the typical vasculopathy-related manifestations of SSc, in patients with no chance for lipofilling.

The selective filtration based technology we used produces an autologous cell concentrate wich contains PB-MNCs plus $1 \%$ around of CD34+ [13]. Despite the efficiency in CD34 + hematopoietic stem cell enrichment with the use of Bone Marrow Point of Care system is comparable to the enrichment obtained 
by Pall Celeris system [62], several studies showed that limb savage was not correlated to CD34 + concentration $[16,48,63,64]$.

In addition of angiogenic ability, PB-MNCs mechanism of action is based also on tissue regeneration due to immune-modulation and paracrine release of growth factors, cytokines, chemokines $[19,20]$.

Monocytes give rise to mature macrophages which are also heterogeneous themselves, although the physiological relevance of this is not completely understood [65]. Far to be a homogeneous population, macrophages display a wide range of phenotypes and physiological properties depending on the cytokines inducing their maturation [66]. They can adopt a variety of different phenotypes in response to different stimuli. Two of the best-characterized in vitro phenotypes are a proinflammatory "M1" phenotype, produced by exposure to IFN- $y$ and TNF- $\alpha$ and hypoxia, and an anti-inflammatory "M2" phenotype, produced by IL-4 or IL-13. M1 are the predominant population present during the first few days after injury, corresponding to the inflammatory and early proliferative phases, whereas $\mathrm{M} 2$ are the primary effectors of the later stages of repair or the later proliferative and remodeling phases. In fact, M2 are frequently termed "wound healing" macrophages, as they express factors that are important for tissue repair $[30,67,68]$.

Macrophages interact with other cell types through paracrine factors to control reepithelialisation, angiogenesis and extracellular matrix remodelling, and several studies have analysed the difficulties in skin wound healing upon macrophage depletion [69-72].

Macrophages play key roles in tissue homeostasis and immune surveillance in response to microbial assault and are fundamental in promoting wound healing to repair damaged tissue [22, 73]. Failure to resolve macrophage activation can lead to chronic inflammation and fibrosis, and ultimately to pathology. PB-MNCs implant induces tissue regeneration through immune-modulation (M1 to M2 polarization) $[22,51,74,75]$.

In particular PB-MNCs produced by selective filtration implanted perilesionally in non healing diabetic foot ulcers were able to polarize M1 to M2 phenotype inducing complete healing [51]. Activated M1 macrophages have been implicated in the pathogenesis of systemic sclerosis ${ }^{[54],[55]}$. Thererefore targeting therapeutic interventions directed against SSc inflammatory M1 macrophages may ameliorate inflammation and fibrosis [76].

The PB-MNCs ability to induce the shift from M1 to M2 causing tissue regeneration could explain the healing of the digital results we obtained. We recorded a lower frequency of Raynaud's phenomenon, together with a significant improvement in hand function. We also observed a mouth opening improvement in the two patients who received the treatment in this area. Furthermore, we observed a significant improvement of all the parameters evaluated, including a meaningful increase of the HAQ-DI composite score. 
This study clearly presents a high criticality due to the low number of patients treated. Moreover, this is a preliminary and observational study wich is lacking in a control group. Despite this, the preliminary results on these critical patients non-responders to standard therapies and with no chance for lipofilling, are encouraging. Our results are in agreement with the observations in two case reports showing an improvement in vascularization and digital ulceration in systemic sclerosis patients $[77,78]$. Results are also in line with suggestive result of PB-MNCs on others auto-immune disease like Thromboangitis Obliterans $[16,77]$.

\section{Conclusions}

The great vasculogenic angiogenic capacity of monocytes/macrophages together with their key role in immune-modulation have been demonstrated in numerous different clinical settings [79-85]. On the whole, evidence highlights M1 and M2 macrophages as important targets for immunotherapy [30]. In our preliminary study, PB-MNCs injection effectively increased all the primary outcomes of the study despite a low level of evidence due to the small sample size. These results suggest that PB-MNCs injection could represent a treatment option to be considered for SSc patients. The procedure we used, is easy and fast to perform, minimally invasive, not-operator dependent, safe and effective in treating mouth opening, Raynaud's phenomenon, digital ulcers and hand movement impairment. Further studies are necessary to confirm these preliminary positive outcomes.

\section{Abbreviations}

SSC

Systemic sclerosis

PB-MNCs

peripheral blood mononuclear cells

HAQ-DI

Health Assessment Questionnaire Disability Index

SHAQ

scleroderma Health Assessment Questionnaire

HAMIS

Hand Mobility in Scleroderma

ACR

American College of Rheumatology

EULAR/ACR

European League Against Rheumatism/ American College of Rheumatology

SVF

Stromal Vascular Fraction

ASCs

Adipose-derived Stomal Cells 
dcSSc

diffuse cutaneous Scleroderma

VAS

Visual Analogue Scale

FACS

Fluoresence-Activated Cell Sorting

TNCs

Total Nuclear Cells

MNCs

Mononuclear Cells

MSCs

Mesenchymal tromal Cells

GMP

Good Manufacturing Practice

\section{Declarations}

\section{Ethics approval and consent to participate}

Patients agreed by a written informed consent to participate in the study.

\section{Consent for publication}

Consent for publication was obtained from all the patients.

\section{Availability of data and materials}

The data that support the findings of this study are available on request from the corresponding author, [S.C.]. The data are not publicly available because their containing information could compromise the privacy of research participants.

\section{Competing Interests}

The authors declare that they have no competing interests regarding the publication of this article.

\section{Funding Statement}

The authors received no specific funding for this work.

\section{Authors' contributions}


All Authors read and approved the manuscript. S.C. enrolled the patients and was a contributor in treating the patients. She drafted and revised the manuscript. C.R. analyzed and interpreted the patient data regarding the Scleroderma, the treatement and the follow-up visits. She was a major contributor in writing the manuscript. D.R. read and approved the manuscript. M.G.O. performed the treatement and revised and approved the manuscript.

\section{Acknowledgements}

Not applicable.

\section{References}

1. Coral-Alvarado P, Pardo AL, Castaño-Rodriguez N, Rojas-Villarraga A, Anaya J-M. Systemic sclerosis: A world wide global analysis. Clin Rheumatol. 2009;28:757-65. doi:10.1007/s10067-009-1144-9.

2. Chifflot H, Fautrel B, Sordet C, Chatelus E, Sibilia J. Incidence and Prevalence of Systemic Sclerosis: A Systematic Literature Review. Semin Arthritis Rheum. 2008;37:223-35. doi:https://doi.org/10.1016/j.semarthrit.2007.05.003.

3. Gaubitz M. Epidemiology of connective tissue disorders. Rheumatology. 2006;45 suppl_3:iii3-4. doi:10.1093/rheumatology/kel282.

4. Jordan S, Maurer B, Toniolo M, Michel B, Distler O. Performance of the new ACR/EULAR classification criteria for systemic sclerosis in clinical practice. Rheumatology. 2015;54:1454-8. doi:10.1093/rheumatology/keu530.

5. Sobolewski P, Maślińska M, Wieczorek M, Łagun Z, Malewska A, Roszkiewicz M, et al. Systemic sclerosis - multidisciplinary disease: clinical features and treatment. Reumatologia/Rheumatology. 2019;57:221-33. doi:10.5114/reum.2019.87619.

6. Giuggioli D, Manfredi A, Lumetti F, Colaci M, Ferri C. Scleroderma skin ulcers definition, classification and treatment strategies our experience and review of the literature. Autoimmun Rev. 2018;17:15564. doi:https://doi.org/10.1016/j.autrev.2017.11.020.

7. Song JI, Volz S, Liodaki ME, Mailander P, Kalousis K. Stem cells therapy: the future in the management of systemic sclerosis? A case report. Hell J Nucl Med. 2017;20 Suppl:164.

8. Guillaume-Jugnot P, Daumas A, Magalon J, Sautereau N, Veran J, Magalon G, et al. State of the art. Autologous fat graft and adipose tissue-derived stromal vascular fraction injection for hand therapy in systemic sclerosis patients. Curr Res Transl Med. 2016;64:35-42. doi:https://doi.org/10.1016/j.retram.2016.01.006.

9. Magalon G, Daumas A, Sautereau N, Magalon J, Sabatier F, Granel B. Regenerative Approach to Scleroderma with Fat Grafting. Clin Plast Surg. 2015;42:353-64. doi:10.1016/j.cps.2015.03.009.

10. Magalon J, Velier M, Simoncini S, François P, Bertrand B, Daumas A, et al. Molecular profile and proangiogenic activity of the adipose-derived stromal vascular fraction used as an autologous 
innovative medicinal product in patients with systemic sclerosis. Ann Rheum Dis. 2019;78:391 LP 398. doi:10.1136/annrheumdis-2018-214218.

11. Scuderi N, Ceccarelli S, Onesti MG, Fioramonti P, Guidi C, Romano F, et al. Human Adipose-Derived Stromal Cells for Cell-Based Therapies in the Treatment of Systemic Sclerosis. Cell Transplant. 2013;22:779-95. doi:10.3727/096368912X639017.

12. Onesti MG, Fioramonti P, Carella S, Fino P, Marchese C, Scuderi N. Improvement of Mouth Functional Disability in Systemic Sclerosis Patients over One Year in a Trial of Fat Transplantation versus Adipose-Derived Stromal Cells. Stem Cells Int. 2016;2016:2416192.

13. Spaltro G, Straino S, Gambini E, Bassetti B, Persico L, Zoli S, et al. Characterization of the Pall Celeris system as a point-of-care device for therapeutic angiogenesis. J Cytotherapy. 2015;17:1302-13.

14. De Angelis B, Gentile P, Orlandi F, Bocchini I, Di Pasquali C, Agovino A, et al. Limb Rescue: A New Autologous-Peripheral Blood Mononuclear Cells Technology in Critical Limb Ischemia and Chronic Ulcers. Tissue Eng Part C Methods. 2015;21:423-35.

15. Persiani F, Paolini A, Camilli D, Mascellari L, Platone A, Magenta A, et al. Peripheral Blood Mononuclear Cells Therapy for Treatment of Lower Limb Ischemia in Diabetic Patients: A SingleCenter Experience. Ann Vasc Surg. 2018;53:190-6.

16. Moriya J, Minamino T, Tateno K, Shimizu N, Kuwabara Y, Sato Y, et al. Long-term outcome of therapeutic neovascularization using peripheral blood mononuclear cells for limb ischemia. Circ Cardiovasc Interv. 2009;2:245-54.

17. Patel AS, Smith A, Nucera S, Biziato D, Saha P, Attia RQ, et al. TIE2-expressing monocytes/macrophages regulate revascularization of the ischemic limb. EMBO Mol Med. 2013;5:858-69.

18. Krishnasamy K, Limbourg A, Kapanadze T, Gamrekelashvili J, Beger C, Häger C, et al. Blood vessel control of macrophage maturation promotes arteriogenesis in ischemia. Nat Commun. 2017;8:952.

19. Beer L, Mildner M, Gyöngyösi M, Ankersmit HJ. Peripheral blood mononuclear cell secretome for tissue repair. Apoptosis. 2016;21:1336-53.

20. Baer C, Squadrito ML, Iruela-Arispe ML, De Palma M. Reciprocal interactions between endothelial cells and macrophages in angiogenic vascular niches. Experimental Cell Research. 2013;319:162634.

21. Gurevich DB, Severn CE, Twomey C, Greenhough A, Cash J, Toye AM, et al. Live imaging of wound angiogenesis reveals macrophage orchestrated vessel sprouting and regression. EMBO J. 2018;::e97786.

22. Krzyszczyk P, Schloss R, Palmer A, Berthiaume F. The role of macrophages in acute and chronic wound healing and interventions to promote pro-wound healing phenotypes. Front Physiol. 2018;9 MAY:419.

23. Li J, Tan J, Martino MM, Lui KO. Regulatory T-cells: Potential regulator of tissue repair and regeneration. Frontiers in Immunology. 2018. 
24. Stabile E, Kinnaird T, La Sala A, Hanson SK, Watkins C, Campia U, et al. CD8+ T lymphocytes regulate the arteriogenic response to ischemia by infiltrating the site of collateral vessel development and recruiting CD4+ mononuclear cells through the expression of interleukin-16. Circulation. 2006;113:118-24.

25. Hellingman AA, Zwaginga JJ, Van Beem RT, Hamming JF, Fibbe WE, Quax PHA, et al. T-cell-prestimulated monocytes promote neovascularisation in a murine hind limb ischaemia model. Eur $\mathrm{J}$ Vasc Endovasc Surg. 2011;41:418-28.

26. Sharma A, Rudra D. Emerging Functions of Regulatory T Cells in Tissue Homeostasis. Front Immunol. 2018;9:883.

27. Kuwana M, Okazaki Y, Yasuoka H, Kawakami Y, Ikeda Y. Defective vasculogenesis in systemic sclerosis. Lancet. 2004.

28. Fleming JN, Nash RA, McLeod DO, Florentino DF, Shulman HM, Connolly MK, et al. Capillary regeneration in scleroderma: Stem cell therapy reverses phenotype? PLoS One. 2008;3.

29. Avouac J, Wipff J, Goldman O, Ruiz B, Couraud PO, Chiocchia G, et al. Angiogenesis in systemic sclerosis: Impaired expression of vascular endothelial growth factor receptor 1 in endothelial progenitor-derived cells under hypoxic conditions. Arthritis Rheum. 2008.

30. Funes SC, Rios M, Escobar-Vera J, Kalergis AM. Implications of macrophage polarization in autoimmunity. Immunology. 2018;154:186-195.

31. van den Hoogen F, Khanna D, Fransen J, Johnson SR, Baron M, Tyndall A, et al. 2013 classification criteria for systemic sclerosis: an American college of rheumatology/European league against rheumatism collaborative initiative. Ann Rheum Dis. 2013;72:1747 LP - 1755. doi:10.1136/annrheumdis-2013-204424.

32. LeRoy EC, Black C, Fleischmajer R, Jablonska S, Krieg T, Medsger TAJ, et al. Scleroderma (systemic sclerosis): classification, subsets and pathogenesis. J Rheumatol. 1988;15:202-5.

33. LeRoy EC, Medsger TA. Criteria for the classification of early systemic sclerosis. J Rheumatol. 2001;28:1573 LP - 1576. http://www.jrheum.org/content/28/7/1573.abstract.

34. Johnson SR, Hawker GA, Davis AM. The health assessment questionnaire disability index and scleroderma health assessment questionnaire in scleroderma trials: An evaluation of their measurement properties. Arthritis Care Res (Hoboken). 2005;53:256-62. doi:10.1002/art.21084.

35. Steen VD, Medsger Jr. TA. The value of the health assessment questionnaire and special patientgenerated scales to demonstrate change in systemic sclerosis patients over time. Arthritis Rheum. 1997;40:1984-91. doi:10.1002/art.1780401110.

36. Del Rosso A, Maddali-Bongi S, Sigismondi F, Miniati I, Bandinelli F, Matucci-Cerinic M. The Italian version of the Hand Mobility in Scleroderma (HAMIS) test: evidence for its validity and reliability. Clin Exp Rheumatol. 2010;28 5 Suppl 62:S42-7.

37. Bianchi F, Maioli M, Leonardi E, Olivi E, Pasquinelli G, Valente S, et al. A new nonenzymatic method and device to obtain a fat tissue derivative highly enriched in pericyte-like elements by mild mechanical forces from human lipoaspirates. Cell Transplant. 2013;22:2063-77. 
38. Pilny E, Smolarczyk R, Jarosz-Biej M, Hadyk A, Skorupa A, Ciszek M, et al. Human ADSC xenograft through IL-6 secretion activates M2 macrophages responsible for the repair of damaged muscle tissue. Stem Cell Res Ther. 2019;10:93.

39. Heo JS, Choi Y, Kim HO. Adipose-Derived Mesenchymal Stem Cells Promote M2 Macrophage Phenotype through Exosomes. Stem Cells Int. 2019;2019:1-10.

40. Xiaoning He, Zhiwei Dong, Yina Cao, Han Wang, Shiyu Liu, Li Liao YJ, Lin Yuan and Bei Li. MSCDerived Exosome Promotes M2 Polarization and Enhances Cutaneous Wound Healing. Stem Cells Int. 2019;2019.

41. Faulknor RA, Olekson MA, Ekwueme EC, Krzyszczyk P, Freeman JW, Berthiaume F. Hypoxia impairs mesenchymal stromal cell-induced macrophage M1 to M2 transition. Technol (Singap World Sci). 2017;05:81-6.

42. Moreno-Moral A, Bagnati M, Koturan S, Ko J-H, Fonseca C, Harmston N, et al. Changes in macrophage transcriptome associate with systemic sclerosis and mediate GSDMA contribution to disease risk. Ann Rheum Dis. 2018;77:596-601.

43. Kubo M, Li TS, Suzuki R, Shirasawa B, Morikage N, Ohshima M, et al. Hypoxic preconditioning increases survival and angiogenic potency of peripheral blood mononuclear cells via oxidative stress resistance. Am J Physiol Circ Physiol. 2008;294:H590-5.

44. Kudo T, Kubo M, Katsura S, Nishimoto A, Ueno K, Samura M. Hypoxically preconditioned human peripheral blood mononuclear cells improve blood flow in hindlimb ischemia xenograft model. 2014;6:570-9.

45. Liu YX, Guo XM, Li JF, Meng Y, Zhang HT, Liu AJ, et al. Restoration of tissue damage, and never activity after hypoxia-ischemia by implantation of peripheral blood mononuclear cells. Brain Res. 2014;1546:34-45.

46. Vaibhav K, Braun M, Khan MB, Fatima S, Saad N, Shankar A, et al. Remote ischemic postconditioning promotes hematoma resolution via AMPK-dependent immune regulation. J Exp Med. 2018;215:2636-54.

47. Navarro A, Marín S, Riol N, Carbonell-Uberos F, Miñana MD. Human adipose tissue-resident monocytes exhibit an endothelial-like phenotype and display angiogenic properties. Stem Cell Res Ther. 2014;5:1-16.

48. Rigato M, Monami M, Fadini GP. Autologous Cell Therapy for Peripheral Arterial Disease: Systematic Review and Meta-Analysis of Randomized, Nonrandomized, and Noncontrolled Studies. Circulation Research. 2017;120:1326-40.

49. Dubsky MD, Jirkovská A, Bem R, Nemcová A, Fejfarová V, Jude EB. Cell therapy of critical limb ischemia in diabetic patients-State of art. Diabetes Res Clin Pract. 2017;126:263-71.

50. Dubsky M, Jirkovska A, Bem R, Fejfarova V, Pagacova L, Sixta B, et al. Both autologous bone marrow mononuclear cell and peripheral blood progenitor cell therapies similarly improve ischaemia in patients with diabetic foot in comparison with control treatment. Diabetes Metab Res Rev. 2013;29:369-76. doi:10.1002/dmrr.2399. 
51. Di Pardo A, Cappello E, Pepe G, Marracino F, Carrieri V, Maglione V, et al. Infusion of autologousperipheral blood mononuclear cells: a new approach for limb salvage in patients with diabetes. In: 7th International Diabetic Foot Congress abu Dhabi. IFD Congress Abu Dhabi 4-8 December 2017; 2017. p. International Diabetic Foot Congress Abu Dhabi 4-8.

52. Colonna MR, Flavia L, Gabriele D, Colonna MR, Flavia L, Gabriele D, et al. Regenerative Approaches Regenerative in Wound Healing: New New Alternatives for Older Tools. In: IntechOpen, editor. Wound Healing- New Insight into Ancient Challenges. Intech; 2016. p. 155-63.

53. Palermo Chiara, Sanfiorenzo Angelo, Trigona Cristina, Bernardini Giulia VP. Role of Monocytes in the Treatment of Chronic Limb Ischemia and “Hard to Heal” Ulcers. J Vasc Surg. 2018;68:e119.

54. Fung E, Helisch A. Macrophages in collateral arteriogenesis. Front Physiol. 2012;3 SEP September:111.

55. Lee C, Schlereth SL, Park EY, Emami-Naeini P, Chauhan SK, Dana R. A Novel Pro-Angiogenic Function for Interferon-Y-Secreting Natural Killer Cells. Investig Opthalmology Vis Sci. 2014;55:2885.

56. Liang C, Yang KY, Chan VW, Li X, Fung THW, Wu Y, et al. CD8+ T-cell plasticity regulates vascular regeneration in type-2 diabetes. Theranostics. 2020;10:4217-32.

57. Kwee BJ, Seo BR, Najibi AJ, Li AW, Shih T-Y, White D, et al. Treating ischemia via recruitment of antigen-specific T cells. 2019.

58. Van Weel V, Toes REM, Seghers L, Deckers MML, De Vries MR, Eilers PH, et al. Natural killer cells and CD4+ T-cells modulate collateral artery development. Arterioscler Thromb Vasc Biol. 2007;27:23108.

59. Fantin A, Vieira JM, Gestri G, Denti L, Schwarz Q, Prykhozhij S, et al. Tissue macrophages act as cellular chaperones for vascular anastomosis downstream of VEGF-mediated endothelial tip cell induction. Blood. 2010;116:829-40.

60. Ryu JC, Davidson BP, Xie A, Qi Y, Zha D, Belcik JT, et al. Molecular imaging of the paracrine proangiogenic effects of progenitor cell therapy in limb ischemia. Circulation. 2013;127:710-9.

61. Jalees R, Jingling L, M. OC, L. MK. Peripheral Blood “Endothelial Progenitor Cells" Are Derived From Monocyte/Macrophages and Secrete Angiogenic Growth Factors. Circulation. 2003;107:1164-9. doi:10.1161/01.CIR.0000058702.69484.A0.

62. Prochazka V, Gumulec J, Jaluvka F, Salounova D, Jonszta T, Czerny D, et al. Cell therapy, a new standard in management of chronic critical limb ischemia and foot ulcer. Cell Transplant. 2010;19:1413-24.

63. Liotta F. Therapeutic Efficacy of Autologous Non-Mobilized Enriched Circulating Endothelial Progenitors in Patients With Critical Limb Ischemia —THE SCELTA TRIAL. Circ J. 2018;82 June:1688-98.

64. Dong Z, Fang Y, Pan T, Liu H, Wei Z, Gu S, et al. Autotransplantation of Purified CD34+Cells for Critical Limb Ischemia Caused by Buerger Disease. Cytotherapy. 2019;21:S55.

65. Gordon S, Taylor PR. Monocyte and macrophage heterogeneity. Nat Rev Immunol. 2005;5:953-64. 
66. Rodero MP, Khosrotehrani K. Skin wound healing modulation by macrophages. Int J Clin Exp Pathol. 2010;3:643-53.

67. Novak ML, Koh TJ. Macrophage phenotypes during tissue repair. J Leukoc Biol. 2013;93:875-81.

68. Wynn TA, Vannella KM. Review Macrophages in Tissue Repair, Regeneration, and Fibrosis. 2016.

69. Rodero MP, Licata F, Poupel L, Hamon P, Khosrotehrani K, Combadiere C, et al. In vivo imaging reveals a pioneer wave of monocyte recruitment into mouse skin wounds. PLoS One. 2014;9:e108212.

70. Rodero MP, Legrand JMD, Bou-Gharios G, Khosrotehrani K. Wound-associated macrophages control collagen 1a2 transcription during the early stages of skin wound healing. Experimental Dermatology. 2013.

71. De La Durantaye M, Piette AB, Van Rooijen N, Frenette J. Macrophage depletion reduces cell proliferation and extracellular matrix accumulation but increases the ultimate tensile strength of injured Achilles tendons. J Orthop Res. 2014;32:279-85.

72. Lucas T, Waisman A, Ranjan R, Roes J, Krieg T, Müller W, et al. Differential Roles of Macrophages in Diverse Phases of Skin Repair. 2014.

73. Wynn TA, Chawla A, Pollard JW. Macrophage biology in development, homeostasis and disease. Nature. 2013;496:445-55.

74. Arnold L, Henry A, Poron F, Baba-Amer Y, Van Rooijen N, Plonquet A, et al. Inflammatory monocytes recruited after skeletal muscle injury switch into antiinflammatory macrophages to support myogenesis. J Exp Med. 2007;204:1057-69.

75. Italiani P, Boraschi D. From monocytes to M1/M2 macrophages: Phenotypical vs. functional differentiation. Frontiers in Immunology. 2014.

76. Toledo DM, Pioli PA. Macrophages in Systemic Sclerosis: Novel Insights and Therapeutic Implications. Current Rheumatology Reports. 2019;21.

77. Kamata Y, Takahashi Y, Iwamoto M, Matsui K, Murakami Y, Muroi K, et al. Local implantation of autologous mononuclear cells from bone marrow and peripheral blood for treatment of ischaemic digits in patients with connective tissue diseases. Rheumatology. 2007;46:882-4. doi:10.1093/rheumatology/kel436.

78. Nevskaya T, Ananieva L, Bykovskaia S, Eremin I, Karandashov E, Khrennikov J, et al. Autologous progenitor cell implantation as a novel therapeutic intervention for ischaemic digits in systemic sclerosis. Rheumatology. 2008;48:61-4. doi:10.1093/rheumatology/ken407.

79. Julier Z, Park AJ, Briquez PS, Martino MM, Julier Z, Park AJ, et al. Promoting tissue regeneration by modulating the immune system. Acta Biomater. 2017;53 January:13-28.

80. Wynn TA, Vannella KM. Macrophages in Tissue Repair, Regeneration, and Fibrosis. Immunity. 2016;44:450-62.

81. Chazaud B. Macrophages: Supportive cells for tissue repair and regeneration. Immunobiology. 2014;219:172-8. 
82. Ogle ME, Segar CE, Sridhar S, Botchwey EA. Monocytes and macrophages in tissue repair: Implications for immunoregenerative biomaterial design. Experimental Biology and Medicine. 2016;241:1084-97.

83. Spiller KL, Koh TJ. Macrophage-based therapeutic strategies in regenerative medicine. Adv Drug Deliv Rev. 2017;122:74-83.

84. Godwin JW, Pinto AR, Rosenthal NA. Chasing the recipe for a pro-regenerative immune system. Semin Cell Dev Biol. 2017;61:71-9.

85. Vagnozzi RJ, Maillet M, Sargent MA, Khalil H, Johansen AKZ, Schwanekamp JA, et al. An acute immune response underlies the benefit of cardiac stem cell therapy. Nature. 2020;577:405-9.

\section{Tables}

Table 1. Patients' data.

\begin{tabular}{|llll|}
\hline Patient & Age & Disease duration & Treated area \\
\hline 1 & 68 & 6 years & Hands \\
\hline 2 & 65 & 11 years & Hands \\
\hline 3 & 49 & 8 years & Hands and mouth \\
\hline 4 & 47 & 8.5 years & Hands \\
\hline 5 & 39 & 4.5 years & Hands \\
\hline 6 & 50 & 6 years & Hands \\
\hline 7 & 44 & 7 years & Hands \\
\hline 8 & 21 & 3 years & Hands \\
\hline 9 & 56 & 9 years & Hands and mouth \\
\hline 10 & 63 & 7 years & Hands \\
\hline
\end{tabular}

Table 2. Hand Mobility In Scleroderma (HAMIS) test. 


\section{Finger flection}

(All fingers must be tight to the object)

0 - Can bend fingers 2-5 around a pencil ( $5 \mathrm{~mm}$ diam)

1- Can bend fingers $2-5$ around a piece of cutlery ( $15 \mathrm{~mm}$ diam)

2 - Can bend fingers 2-5 around handlebar ( $30 \mathrm{~mm}$ diam)

3 - Cannot manage the previous item

\section{Finger extension}

0 - Can feel the table completely with digits $2-5$

1 - Can feel the pencil ( $5 \mathrm{~mm}$ diam) with digits $2-5$

2 - Can feel the piece of cutlery ( $15 \mathrm{~mm}$ diam) with digits $2-5$

3 - Cannot manage the previous item

\section{Thumb abduction}

0 - Can grip around a coffee package (90 $\mathrm{mm}$ diam)

1 - Can grip around a milk parcel (70 mm diam)

2 - Can grip around a bottle (60 $\mathrm{mm}$ diam)

3 - Cannot manage the previous item

\section{Pincer grip}

0 - Can form a round pincer grip

1 - Can form a D-shaped pincer grip

2 - Can form a long narrow pincer grip

3 - Cannot manage the previous item

\section{Finger abduction}

0 - Can spread the fingers and then fold the hands together to the bottom of the fingers

1 - Can spread the fingers and then fold the hands together to the first phalanx

2 - Can spread the fingers and then fold the hands together to the second phalanx

3 - Cannot manage the previous item

\section{Volar flexion}

(The person stands with the arms alongside the body. The object is given from behind)

0 - Can grasp a spool of thread with a slight flexion of MCP and extended PIP and DIP joints

1 - Can grasp a spool of thread with a large flexion of MCP and ectended PIP and DIP joints 


\section{2 - Can grasp a spool of thread with a large flexion of MCP and flexion PIP \\ 3 - Cannot manage the previous item}

\section{Dorsal extension}

0 - Can hold the palms together and put the wrists against the stomach

1 - Can hold the palms together and put the thumbs against the throat

2 - Can hold the palms together and put the thumbs up to the mouth

3 - Cannot manage the previous item

\section{Pronation}

0 - Can put the palms of the hands on the table (MCP 2-5 must touch the surface)

1 - Can put the palms of the hands on the table (MCP 3-5 must touch the surface)

2 - Can put the palms of the hands on the table (MCP 4-5 must touch the surface)

3 - Cannot manage the previous item

\section{Supination}

0 - Can put the backs of the hands on the table (MCP 2-5 must touch the surface)

1 - Can put the backs of the hands on the table (MCP 3-5 must touch the surface)

2 - Can put the backs of the hands on the table (MCP 4-5 must touch the surface)

3 - Cannot manage the previous item

MCP: Metacarpophalangeal joints, PIP: Proximal interphalahgeal joints, DID: Distal interphalangeal joints

\section{Table 3. Patients' clinical outcomes.}




\begin{tabular}{|lllllllll|}
\hline Patient & $\begin{array}{l}\text { HAMIS Scale } \\
\text { (0-27) }\end{array}$ & & $\begin{array}{l}\text { Raynaud's phenomenon (episodes } \\
\text { per day) }\end{array}$ & & $\begin{array}{l}\text { Digital ulcers } \\
\text { (annual } \\
\text { incidence) }\end{array}$ & $\begin{array}{l}\text { HAQ-DI } \\
\text { score }\end{array}$ \\
\hline & $\begin{array}{l}\text { T0 } \\
(\mathrm{dx} / \mathrm{sn})\end{array}$ & $\begin{array}{l}\mathrm{T} 5 \\
(\mathrm{dx} / \mathrm{sn})\end{array}$ & T0 & T5 & T0 & T5 & T0 & T5 \\
\hline 1 & $10 / 10$ & $4 / 4$ & 8 & 3 & 5 & 1 & 0.54 & 0.34 \\
\hline 2 & $6 / 6$ & $2 / 2$ & 9 & 2 & 2 & 0 & 0.57 & 0.23 \\
\hline 3 & $8 / 8$ & $3 / 3$ & 7 & 1 & 0 & 0 & 0.75 & 0.31 \\
\hline 4 & $11 / 11$ & $7 / 7$ & 15 & 5 & 1 & 0 & 1.22 & 0.56 \\
\hline 5 & $7 / 7$ & $2 / 2$ & 9 & 3 & 3 & 1 & 0.85 & 0.43 \\
\hline 6 & $6 / 6$ & $2 / 2$ & 8 & 2 & 0 & 0 & 0.47 & 0.22 \\
\hline 7 & $9 / 9$ & $3 / 3$ & 6 & 0 & 1 & 0 & 0.54 & 0.32 \\
\hline 8 & $7 / 7$ & $3 / 3$ & 7 & 2 & 0 & 0 & 0.53 & 0.28 \\
\hline 9 & $8 / 8$ & $4 / 4$ & 8 & 2 & 2 & 1 & 0.77 & 0.52 \\
\hline 10 & $9 / 9$ & $6 / 6$ & 9 & 4 & 0 & 0 & 0.80 & 0.43 \\
\hline
\end{tabular}

${ }^{1}$ Hand Mobility In Scleroderma (HAMIS) Scale

${ }^{2}$ Health Assessment Questionnaire (HAQ) Disability Index (DI)

\section{Figures}

A

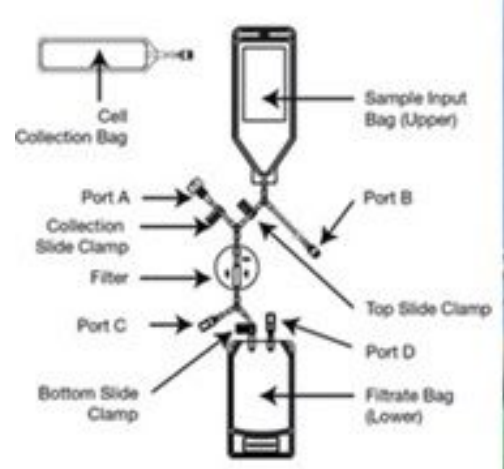

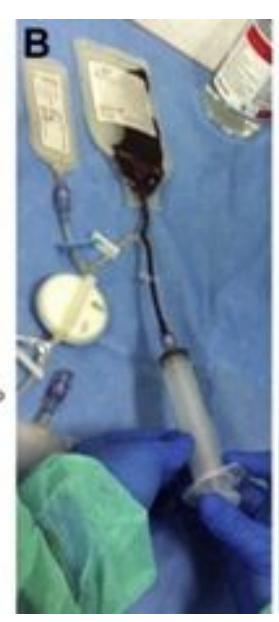

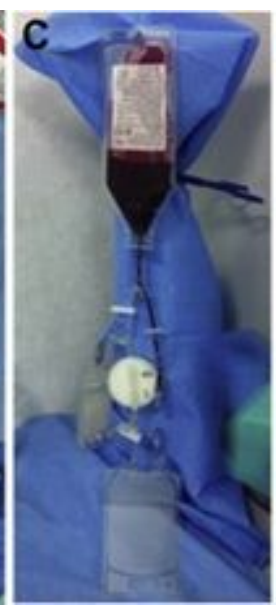

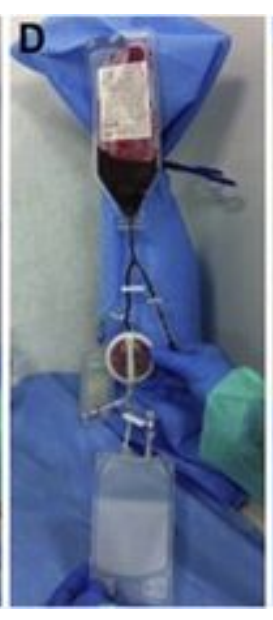

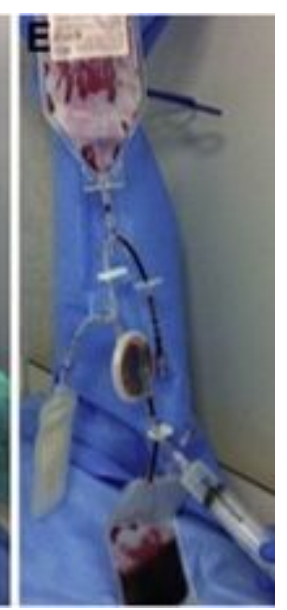

Figure 1

Pall Celeris system 


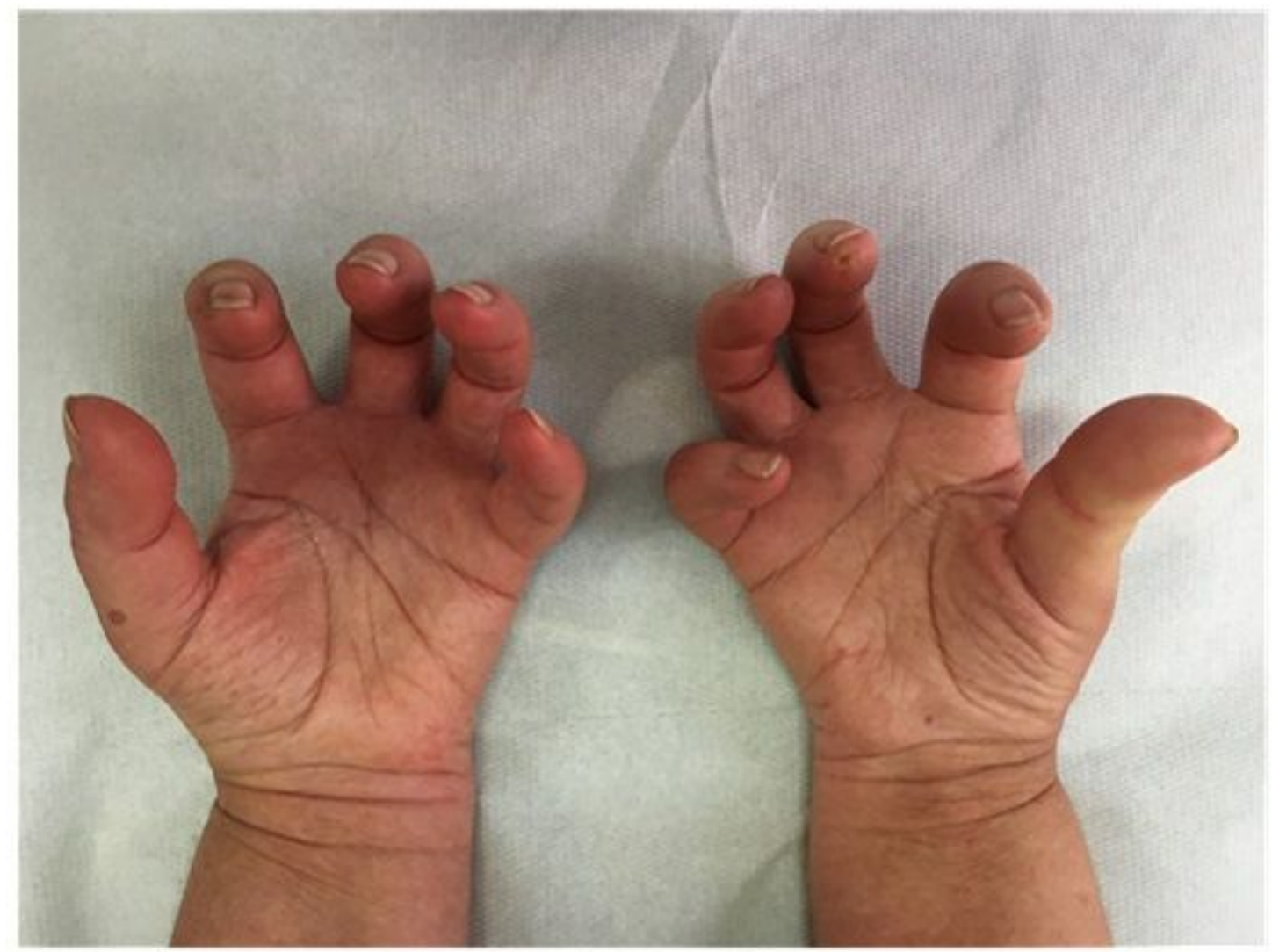

Figure 2

Pre-treatement appereance in patient with digital ulcer on the third right finger

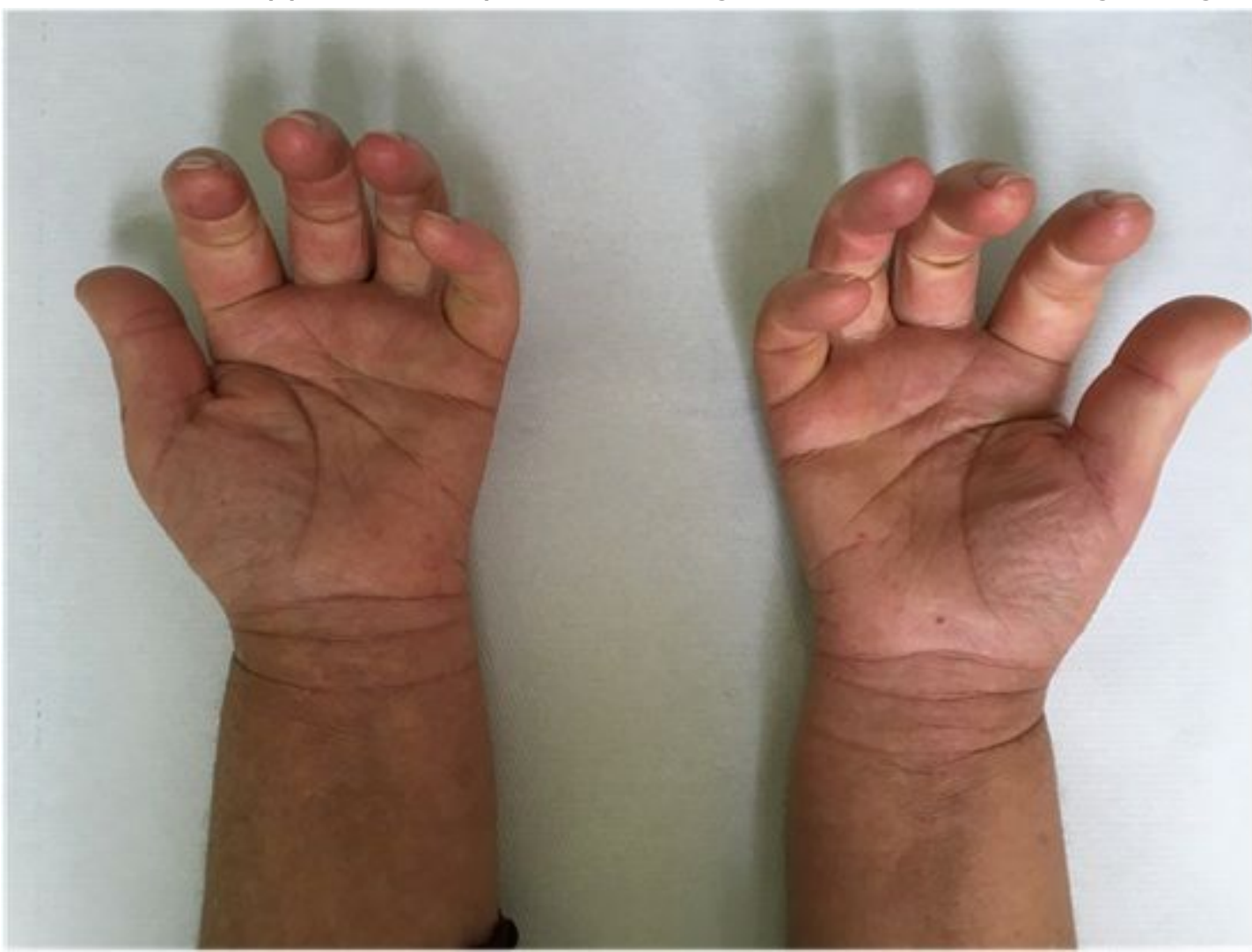


Figure 3

Healed ulcer after the treatement.
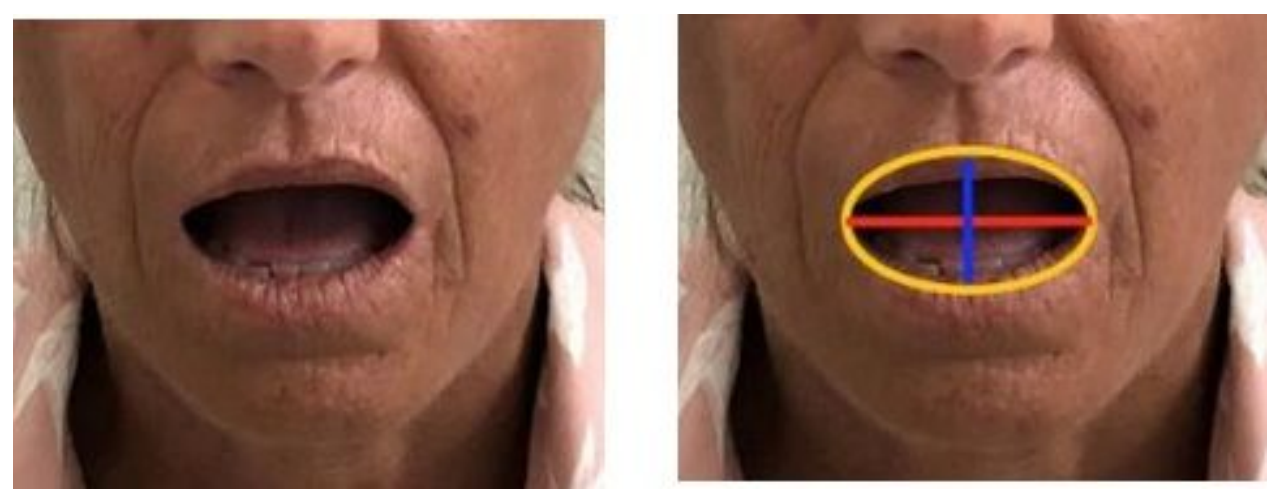

\section{Figure 4}

Pre-treatement appereance in patient with mouth opening impairement. Patient A - T0: half of the distance between the lip commissures: $2 \mathrm{~cm}$; half of the distance between upper and lower lip: 1,45 cm. Ellipse Perimeter $=10,84 \mathrm{~cm}$.
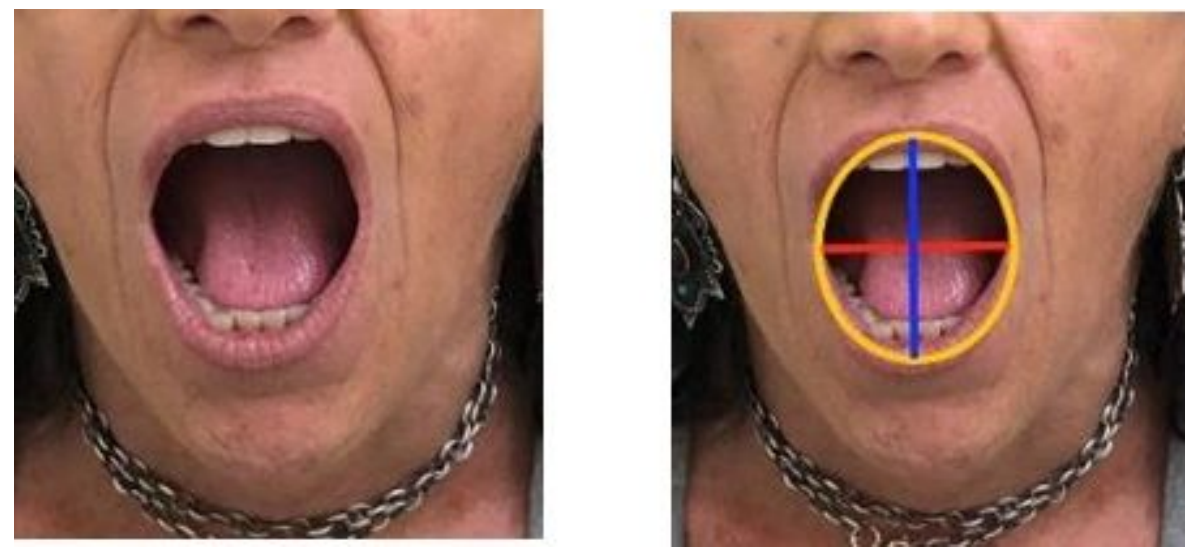

\section{Figure 5}

Post-treatement appereance in patient with mouth opening impairement: improvement of mouth opening. Patient A - T5: half of the distance between the lip commissures: $2 \mathrm{~cm}$; half of the distance between upper and lower lip: $2,35 \mathrm{~cm}$. Ellipse Perimeter $=13,66 \mathrm{~cm}$. 